\title{
On the role of Echocardiography and beta-receptors downregulation in multi-pattern takotsubo
}

\author{
Nicola Tarantino ${ }^{1}$, Francesco Santoro ${ }^{2}$, Luigi Di Biase ${ }^{1}$, Domenico Della Rocca ${ }^{3}$, and \\ Natale Daniele Brunetti ${ }^{2}$ \\ ${ }^{1}$ Montefiore Medical Center \\ ${ }^{2}$ University of Foggia \\ ${ }^{3}$ Saint David's Healthcare
}

May 15, 2020

To the Editor:

We enjoyed reading the case, authored by Janus and Hoit, of a 67-year-old woman with a subarachnoid hemorrhage (SAH) who presented with three different variants of takotsubo (TT).[i] We congratulate the authors on their interesting contribution to the literature. We would like to share some comments and questions on the chronology and management of the events between the first two episodes, which occurred a few days apart.

Although fascinating, this is not the first case of TT with a rapidly evolving pattern. We previously described a case of mid-ventricular takotsubo which replaced apical ballooning in 6 hours.[ii] A recent metaanalysis showed that almost $80 \%$ of TT recurrences exhibit a ballooning pattern different from the first presentation. [iii] In this regard, regional cardiac sympathetic innervation remodeling or denervation could hypothetically justify why the same territory is usually spared from further relapses. Even though images were not provided, the authors stated that "echocardiographic wall motion abnormalities quickly resolved after each acute stressor". One could therefore argue that this was not a case of multiple TT variants during the same episode, as noted by Madias, ${ }^{\text {iii }}$ but rather an example of early recurrences. Additionally, if cardiac innervation remodeling were responsible for the different locations of the ballooning, we believe that the change in pattern would have taken longer to manifest. This would not support the observation of two distinct ballooning patterns emerging within days, let alone hours., ii In this case, a short-term change from the mid-ventricular to apical pattern could be reasonably explained by different $\beta$ adrenergic-receptor ( $\beta$-AR) subtype downregulation. We know that norepinephrine can downregulate $\beta 1$-AR after a few hours. Beta1-ARs are markedly lower on biopsied patients with acute TT compared to healthy controls,[iv] whilst in the same study $\beta 2$-ARs expression - which is predominant in the apical and mid-ventricular segments and thought to be involved in typical takotsubo pathogenesis $[\mathrm{v}]$ — was equivalent to normal.

Thus, the sequence of events could be interpreted as a relative local $\beta 2$ prevalence due to dynamic $\beta 1$ downregulation ( $\beta 1: \beta 2$ mismatch), following a base:mid-ventricle, and ultimately a mid-ventricle:apex progression. What do the authors think about this theory? Is it possible that multi-faceted presentations might simply be under-recognized? Should this be the case, how do they think we could better understand this phenomenon in a noninvasive fashion? Could dobutamine stress echocardiography have utility to identify areas of $\beta$-AR downregulation and sympathetic denervation?

It would also be interesting to know more about the patient's medical therapy. Did she receive nonselective $\beta$-blockers, such as labetalol or carvedilol, usually prescribed after SAH? If so, this might indicate that $\beta$-blockers do not prevent recurrences, [vi] but rather create a maladaptive imbalance in regional $\beta 1: \beta 2$ 
distribution favoring early relapse(s), as this case suggests.

\section{References}

[i] Janus SE, Hoit BD. The three faces of takotsubo cardiomyopathy in a single patient. Echocardiography. 2020 Jan;37(1):135-138. doi: 10.1111/echo.14560. Epub 2019 Dec 16.

[ii] Casavecchia G, Zicchino S, Gravina M, et al. Fast 'wandering' Takotsubo syndrome: atypical mixed evolution from apical to mid-ventricular ballooning. Future Cardiol. 2017 Nov;13(6):529-532. doi: 10.2217/fca2017-0018. Epub 2017 Oct 12.

[iii] Madias JE. Comparison of the first episode with the first recurrent episode of takotsubo syndrome in 128 patients from the world literature: Pathophysiologic connotations. Int J Cardiol. 2020 Mar 3. pii: S0167-5273(20)30215-1. doi: 10.1016/j.ijcard.2020.03.003.

[iv] Nakano T, Onoue K, Nakada Y, et al. Alteration of $\beta$-Adrenoceptor Signaling in Left Ventricle of Acute Phase Takotsubo Syndrome: a Human Study. Sci Rep 8, 12731 (2018). https://doi.org/10.1038/s41598018-31034-z.

[v] Paur H, Wright PT, Sikkel MB, et al. High levels of circulating epinephrine trigger apical cardiodepression in a 32 -adrenergic receptor/Gi-dependent manner: a new model of Takotsubo cardiomyopathy. Circulation. 2012 Aug 7;126(6):697-706. doi: 10.1161/CIRCULATIONAHA.112.111591. Epub 2012 Jun 25.

[vi] Santoro F, Ieva R, Musaico F, et al. Lack of efficacy of drug therapy in preventing takotsubo cardiomyopathy recurrence: a meta-analysis. Clin Cardiol. 2014 Jul;37(7):434-9. doi: 10.1002/clc.22280. Epub 2014 Apr 3. 